\title{
ALGUMAS REFLEXÕES SOBRE O MÉTODO DE ESTUDO DE CASOS NO DIREITO / SOME REFLECTIONS ON THE METHOD OF CASE STUDIES IN LAW
}

\author{
Alfredo de J. Flores ${ }^{1}$
}

\section{Resumo}

O presente artigo busca desenvolver reflexões sobre o método de estudos de casos no Direito. Procura-se demonstrar que no método de estudo de casos há um resgate da visão jurídica tradicional. Isto é, o método de estudo de casos manifesta um modelo filosófico tradicional no Direito que surgiu na Antiguidade Clássica e que foi obnubilado pelo discurso iluminista.

Partindo daí, é possível ressaltar que se buscará demonstrar que o estudo de casos demanda um diálogo entre os aspectos particular e universal, o que remonta aos primórdios da experiência jurídica ocidental com o pensamento filosófico grego e o Direito romano.

$\mathrm{O}$ artigo pretende realizar ainda um enquadramento no plano da teoria do conhecimento, com que será possível visualizar tanto os aspectos mais gerais da questão do método como o modo de incidência no caso particular.

Palavras-chave: Metodologia. Estudo de casos. Filosofia jurídica clássica. Direito romano.

\section{Abstract}

This article seeks to develop reflections on the method of case studies in Law. It seeks to demonstrate that the method of case study there is a redemption of traditional legal view. The method of case study demonstrates a traditional philosophical model in law that emerged in antiquity and that was clouded by Enlightenment discourse.

Proceeding from this, it is possible to emphasize that seek to demonstrate that the study of cases demand a dialogue between the particular and the universal aspect, which dates back to the beginnings of Western legal experience with Greek philosophical thought and Roman law.

The article intends to carry out a framework in terms of the theory of knowledge, with which you can view both the most general aspects of the question of the method as the mode of incidence in the particular case.

Keywords: Methodology. Case study. Traditional legal philosophy. Roman law.

\footnotetext{
${ }^{1}$ Doutor em Direito pela Universitat de València (Espanha, 2004); Professor Adjunto de Metodologia jurídica (Faculdade de Direito - UFRGS); Professor Permanente do Programa de Pós-Graduação em Direito (PPGDir - UFRGS); Sócio do Instituto de Filosofia e Ciência do Direito - 'Lex et lus' (Porto Alegre); Sócio do Instituto Jacques Maritain do Rio Grande do Sul.
} 


\section{Sumário:}

Introdução

10 enfoque prático

1.1 Análise de casos e o juízo particular

1.2 A dianoia praktike: a razão prática como conhecimento do particular (contingencial)

1.3 A prudência como critério metodológico apropriado para o estudo de casos

20 processo de indução
2.1 A questão da abstração e suas dificuldades
2.2 Confirmação na história da ciência jurídica
2.3 Equívocos da postura moderna relativista (o caso não universalizado): entre o dogmatismo e a necessidade de transformação Conclusão

\section{Introdução}

Tema esquecido durante grande parte da Modernidade, o estudo de casos no Direito atualmente é um assunto de primeira grandeza na metodologia jurídica. Não foi assim em outros tempos: de fato, o que ocorreu foi que o ardor iluminista por uma razão absolutamente teórica muitas vezes levou o pensamento jurídico de então ao desprezo pelo conhecimento do fenômeno jurídico em seus aspectos particulares. No contexto atual, pode-se asseverar que foram várias as circunstâncias que levaram a essa revalorização do caso concreto no conhecimento do Direito; contudo, poder-se-ia perguntar em que medida a atual ênfase no método de estudo de casos resulta somente de um processo de superação de um discurso de caráter dedutivista que foi construído no Jusracionalismo e configurado no Positivismo jurídico.

A esse respeito, é preciso apontar que o estudo de casos não foi um simples corolário da mentalidade empirista típica do modelo de ciência hoje vigente. Pode-se dizer que interessa sim a muitos afirmar que esse empirismo ganhou terreno na área jurídica, pretensamente acompanhando a negação do séc. XX ao idealismo anterior. Mas o que se pretende indicar neste trabalho, mesmo reconhecendo que existe uma influência do discurso científico em voga, é que com o estudo de casos houve um resgate da visão jurídica tradicional. Isto é, o método de estudo de casos manifesta um modelo filosófico tradicional no Direito que surgiu na Antigüidade Clássica e que foi obnubilado pelo discurso iluminista.

Partindo daí, é possível ressaltar que se buscará demonstrar que o estudo de casos demanda um diálogo entre os aspectos particular e universal, o que remonta aos primórdios da experiência jurídica ocidental com o pensamento filosófico grego e o Direito romano. Para alcançar tal meta, deve-se fazer um enquadramento no plano da teoria do conhecimento, com que será possível visualizar tanto os aspectos mais gerais da questão como o modo de incidência no caso particular. 
Dessa forma, a análise a ser feita, que tem natureza filosófica, centra-se em dois aspectos essenciais que explicam esse papel do estudo de casos no diálogo já citado, que seriam o enfoque prático (1) e o processo de indução (2).

\section{0 enfoque prático}

Em uma primeira aproximação ao tema, é de ressaltar-se que o ponto de vista prático ${ }^{2}$ é a melhor forma de chegar a uma compreensão dos atos humanos. Com isso, nota-se que o enquadramento filosófico do estudo de casos tem assento na filosofia prática. Partindo desse enfoque, serão apresentados três pontos que se conectam ao exame deste tema - são eles, o juízo particular (1.1), a natureza da razão prática (1.2) e a virtude da prudência (1.3).

\subsection{Análise de casos e o juízo particular}

Comentando aquela concepção iluminista de definir os limites do fenômeno jurídico desde a razão teórica vinculada à matemática, pode-se, porém, recordar que tal concepção muitas vezes resultava de um reducionismo de determinados autores. Contudo, vale ressaltar que a Escola jusracionalista teve entre seus representantes alguns autores de notável capacidade na teoria, mas também de grande percepção prática. Um exemplo notório é a grande obra de Gottfried Wilhelm Leibniz, a Nova Methodus, quando este autor afirma, no início do texto, que a ciência jurídica ${ }^{2}$ trata do caso, como se nota no original: "jurisprudentia est scientia juris, proposito aliquo casu seu facto" (tradução livre - a ciência a propósito de algum caso ou fato). Essa obra, feita na juventude de Leibniz, em 1667, defende uma avaliação prática da ciência jurídica, mesmo dentro de um contexto histórico idealista, como o do final do séc. XVII.

Tendo em conta o citado exemplo, é possível afirmar que existem autores na Modernidade que não foram tomados pelo discurso revolucionário da ruptura com o passado. Não é por acaso tal definição de Leibniz - nesta mesma obra ele consegue apropriar-se da matéria jurídica do texto justinianeu, planejando uma sistematização

\footnotetext{
${ }^{2}$ Explica John Finnis, na edição em espanhol: "Por 'práctico', aquí como en todo este libro, no quiero decir 'factible' como opuesto a no factible, ni eficiente como opuesto a ineficiente; quiero decir 'con miras a la decisión y a la acción'. El pensamiento práctico es pensar acerca de qué (debe uno) hacer. La razonabilidad práctica es razonabilidad al decidir, al asumir compromisos, al elegir y ejecutar proyectos, y, en general, al actuar. La filosofía práctica es una reflexión disciplinada y crítica sobre los bienes que pueden realizarse en la acción humana y sobre las exigencias de la razonabilidad práctica. De manera que cuando decimos que el teórico descriptivo (cuyos fines no son prácticos) debe proceder, en su indispensable selección y formación de conceptos, adoptando un punto de vista práctico, queremos decir que él debe apreciar la importancia o significación de las semejanzas y las diferencias dentro de su materia de estudio preguntándose qué sería considerado importante o significativo en ese campo por aquellos cuyos intereses, decisiones y actividades crean o constituyen la materia estudiada" (FINNIS, John. Ley natural y derechos naturales. Tradução e estudo preliminar de Cristóbal Orrego. Buenos Aires: Abeledo-Perrot, 2000. p. 46). 2 Segundo a edição que foi publicada em 1748 tendo prefácio feito por Christian Wolf - DE LEIBNIZT, Godofredi Gvilielmi L. B. Nova methodvs discendæ docendæque Ivrisprvdentiæ, ex artis didacticæ principiis in parte generali præpræmissis, experientiæque luce. Lipsiæ et Halæ: Officina Krvgiana, MDCCXXXXVIII, p. 26 (Nachdr. - Glashütten im Taunus: Detlev Auvermann KG, 1974).
} 
desta matéria que parte da realidade histórica. Essa proposta de sistematização teve um caráter doutrinário, mas que veio a consolidar-se no plano legislativo somente no contexto napoleônico, quando surgiu o modelo de código civil que, por sua vez, não teve mais apego àquela razão histórica e prática que havia em Leibniz.

A alusão a um autor tido como racionalista é relevante quando se percebe que a análise de casos não é prerrogativa do pensamento contemporâneo, muito menos em razão do primado de um postulado empirista - na verdade, trata-se de uma secular tradição, que remonta ao pensamento da Antigüidade Clássica e ao Medievo. Por esse motivo, pode-se afirmar que a visão antiga, particularmente a romana, em que é praxe que se denomine de "casuística", já trabalhava com o juízo particular sobre os fenômenos jurídicos. Como se pode notar, é possível dizer que até mesmo determinados representantes modernos da ciência do direito respeitaram tal compreensão, segundo se depreende do exemplo de Leibniz.

\subsection{A dianoia praktike: a razão prática como conhecimento do particular (contingencial)}

Diante dessa percepção histórica, de que o direito trabalha também centrado nos juízos particulares, além logicamente dos universais (no plano teórico-jurídico), entende-se por que ainda é válida a idéia de Aristóteles (na "Ética a Nicômaco" e na "Metafísica") de que, no plano da ação humana - que é o domínio do conhecimento particular - predomina a razão prática (dianoia praktike).

Nesse âmbito, é possível perceber, sempre com Aristóteles, o plano da praxis (a prática) - enquanto aperfeiçoamento do homem, porque é o campo da prudência, o bem agir; este é diferente do plano também contingencial da poiesis (a criação) enquanto construção de objetos. Apesar da mencionada diferença, tais planos estão no âmbito das contingências da vida, em que predomina o uso do juízo particular, não sendo, por isso, universal, porque trata de fenômenos, não de formas abstratas, como ocorre no âmbito da abstração intelectual, a theoria.

\subsection{A prudência como critério metodológico apropriado para o estudo de casos}

Quando se fala sobre o conhecimento do caso concreto, é comum lembrar a visão romana da prudência, que não era um mero atributo, mas realidade, como se percebeu na Roma clássica dos pretores. Valendo-se deste exemplo histórico, da figura do pretor urbano (principalmente na fase in iure do ordo iudiciorum privatorum - do juízo entre privados que era feito na Roma da época), entende-se como essa prudentia, enquanto tradução do termo grego phronesis (que está presente no livro VI da "Ética a Nicômaco"), é a base para estabelecer o conhecimento jurídico. Daí o termo iurisprudentia e sua definição em Ulpiano como "notícia das coisas divinas e humanas" ("iurisprudentia est divinarum atque humanarum rerum notitia" - no início das Instituições de Justiniano), ou seja, conhecimento pleno da vida humana, os aspectos universais e particulares do justo.

Com base nessa compreensão, pode-se anotar que a prudência se apresenta como o critério para o estudo do caso. Para tanto, basta lembrar o famoso jusfilósofo 
australiano John Finnis, quando aponta o enfoque da moralidade (no capítulo 1 da obra "Lei natural e direitos naturais") como primordial para o conhecimento prático. Com isso, Finnis consegue superar os reducionismos contemporâneos que primam por uma posição empirista quando apresenta a figura aristotélica do spoudaios (ou o phronimos, o que age plenamente, o prudente) como o caso central (na linguagem de Herbert Hart) da ação humana e do conhecimento proveniente da razão prática. Por isso, tal proposta de Finnis, a respeito do papel da prudência no conhecimento do fenômeno jurídico ${ }^{3}$, foi recepcionada em vários autores que trabalham nessa mesma temática.

\section{0 processo de indução}

Ao tratar-se de juízos particulares, faz-se necessário citar a questão de como se dá o conhecimento dos mesmos. Neste caso, entra em cena a indução, processo esse discutido na filosofia desde Sócrates (na sua noção de diairesis, que é também central na explicação platônica do conhecimento contingencial) e que traz consigo todo um conjunto de grandes temas, os quais serão apresentados sucintamente na seqüência deste estudo - a questão da abstração (2.1), a experiência jurídica desde a perspectiva histórica (2.2) e o problema do relativismo moderno (2.3).

\subsection{A questão da abstração e suas dificuldades}

O tema da indução, como bem indica Antonio Gómez Robledo ${ }^{4}$, traz à tona 0 processo sensitivo-intelectivo e a abstração. Na linguagem aristotélico-tomista, como muito bem havia manifestado Santiago Ramírez quando ressalta as diferenças entre o particular e o universal ${ }^{5}$, já na cogitativa (que é um sentido interno, capaz de fazer juízos particulares de analogia), percebe-se o problema de ter de abstrair a forma (o que ocorre somente no intelecto) do ser em observação.

Nesses termos, partindo da concepção clássica, compreende-se a relevância de que se reconheça a validade do conhecimento que o ser humano pode ter dos fenômenos. Trata-se de um conhecimento que tem a sua base nos sentidos e que a partir dos mesmos é que se alça ao plano da abstração.

Não obstante recordar isso, é preciso recordar que, em Tomás de Aquino, o conhecimento que se tem da realidade seria o conhecer algo do fenômeno (que é a "quididade" - quidditas). Não seria razoável pensar que o ser humano pode conhecer tudo - na verdade, conhece a forma da coisa ('res'), no sentido que conhece a forma "para si" (conjuntamente com o conhecimento reflexivo do "eu" - isto é, que conheço um objeto e ainda sei também que eu sou distinto do objeto que percebo).

\footnotetext{
${ }^{3}$ Tal concepção é notada em vários autores: pode-se citar o artigo de Fábio Machado como exemplo (MACHADO, Fábio. Do conhecimento jurídico, saber prático-prudencial. Direito \& Justiça. Porto Alegre: EDIPUCRS, v. 31, ano 27, p. 45-65, jul. 2005, p. 47). Pode-se incluir ainda neste mesmo rol a autores que trabalham a questão desde a filosofia, como A. Gómez Robledo (GÓMEZ ROBLEDO, Antonio. Ensayo sobre las virtudes intelectuales. México D.F.: Fondo de Cultura Económica, 1996. p. 193). 4 Idem, p. 77.5

RAMÍREZ, Santiago. El concepto de filosofía. Tradução de J. García López. Madrid: Ed. León, 1953. p. 11.
} 
Isso comprova ademais que o processo de abstração resulta ser realmente um tema difícil de tratar quando se pensa no estudo de casos. Afirma-se isso porque não se presume que o estudo de casos, de natureza particular, seja a única regra - pois, assim, atingiríamos o paradoxo de que o Direito nunca chegaria a um patamar científico. É preciso passar pelos sentidos, percebendo o conjunto do fenômeno que está imbuído da sensibilidade, para então chegar ao universal. Por essa razão, é aí que se percebe a questão da abstração - o modo de chegar-se à forma, à essência do conhecimento.

\subsection{Confirmação na história da ciência jurídica}

O processo de passagem do juízo particular ao universal também foi um tema presente na metodologia jurídica. Poder-se-ia citar o caso romano, em suas regras que são conhecidas dentro do Digesto justinianeu. Obviamente nenhuma doutrina romanística entendeu que a experiência romana fosse de uma construção de regras absolutas e universais. Olhando-se atentamente para a parte do Digesto que retrata as regras do Direito antigo (livro L, título XVII), vê-se aí um conjunto de regras para a aplicação nos casos concretos, mas não é preciso negar que existe um determinado grau de abstração nestas regras romanas.

Dentro de outro cenário, pode-se lembrar que modernamente o ilustre jurista alemão Friedrich Carl von Savigny já acenava para o mesmo caminho, como, por exemplo, quando de seus estudos em Marburg em 1802-1803, coletados por Jacob Grimm no Juristische Methodenlehre (Metodologia jurídica). Ali, o autor reconhece a função da análise dos casos, principalmente no processo de elaboração histórica, quando recorda o papel ${ }^{4}$ da história na construção legislativa, sem esquecer ainda a necessidade de que se deve ponderar a matéria nos âmbitos filológico, histórico e filosófico-sistemático.

Isso que anota Savigny que, diga-se de passagem, foi preocupação constante do autor, desde o famoso Vom Beruf, publicado em 1814, já era realidade no âmbito legislativo da Alemanha de então. Por outro lado, desde uma perspectiva filosófica, a própria história da tradição central do Ocidente (no sentido que indica, por exemplo, Alasdair Maclntyre) sempre teve em conta a busca do diálogo entre o caso concreto e a regra universal. Não por acaso, foi no chamado sistema romano-germânico que ficou consolidada a construção do pensamento jurídico, apesar do influxo dedutivista do lluminismo por um relevante período, separando o plano universal do particular. Assim, tendo em conta esses testemunhos de autores da Modernidade que partiam

\footnotetext{
${ }^{4}$ Ao explicar a elaboração histórica da ciência jurídica, afirma Savigny : "En la jurisprudencia mucho no se puede comprender sin cierto conocimiento histórico previo; pero no se trata aquí de esta utilización de la historia para saber algo acerca de la jurisprudencia, sino que investigamos en la medida en que ésta debe tener un carácter histórico (...). Esta elaboración es absolutamente indispensable, en particular para la legislación justinianea; pues toda legislación es poco más o menos el resultado de la historia anterior de la legislación. Justiniano nunca tuvo la intención de hacer un código propio, sino de formar una mera compilación del rico material existente; el todo histórico se convirtió así nuevamente en ley. Ya de acuerdo con su forma, la legislación justinianea lleva en sí el carácter histórico; por ejemplo, son indicados los nombres de los autores de los fragmentos" (SAVIGNY, Friedrich Carl von. Metodología jurídica. Tradução de J. J. Santa-Pinter. Buenos Aires: Depalma, 1994. p. 30).
} 
de um diálogo com a história, fica registrado que a legislação tem em si a regra geral que deve ser aplicada nos casos particulares, sempre recordando que tal legislação não é mero arbítrio do legislador, mas corresponde ao projeto de construção de leis segundo a cultura de cada povo.

\subsection{Equívocos da postura moderna relativista (o caso não universalizado): entre o dogmatismo e a necessidade de transformação}

Apesar do apelo de Savigny, o discurso que acabou ganhando monta no séc. XIX fez o enquadramento do conhecimento jurídico segundo os rígidos moldes da Escola exegética e do positivismo. Com isso, a dificuldade natural de classificar a matéria jurídica foi subjugada por um dedutivismo ${ }^{7}$ que partia de modelos teóricos construídos, na maioria das vezes, arbitrariamente.

Mesmo com a postura de grandes juristas (como no caso de Augusto Teixeira de Freitas, na Introdução de sua Consolidação de 1857, quando indica os critérios para a classificação ${ }^{5}$ da matéria jurídica), que categoricamente não concordavam com o esquematismo da época, o que se viu no discurso da Pandectística, como se encontra no Lehrbuch des Pandektenrechts de Bernhard Windscheid, foi a apologia da interpretação dogmática, visão essa que até mesmo representantes da corrente positivista ${ }^{67}$ viriam a rejeitar posteriormente. Esse dogmatismo exegético dificultou o conhecimento do Direito, como bem explica o jusfilósofo argentino Rodolfo Vigo ${ }^{10}$, e essa foi a causa da forte ruptura contemporânea (partindo da análise dos casos, em que o contexto histórico demandava ${ }^{8}$ reais transformações sociais) com o discurso dogmático de caráter idealista.

\section{Conclusão}

Em síntese, a proposta deste exame de fazer uma análise do estudo de casos desde a perspectiva da teoria do conhecimento mostra que tal método não foi uma

\footnotetext{
${ }^{5}$ É nesse sentido que comenta Teixeira de Freitas na 'Introdução' da Consolidação, "examinar as leis em seus proprios textos sem influencia de alheias opiniões, comparar attentamente as leis novas com as antigas, medir com precisão o alcance e consequencias de umas e outras, eis o laborioso processo, que empregado temos para conhecer a substancia viva da Legislação. Para achar, porém, os limites do Direito Civil, e a norma da exposição das materias que lhe pertencem, recorremos á estudos de outra natureza, consultámos os monumentos legislativos, revimos e meditamos as tradicções da sciencia, e com toda a liberdade de espirito procuramos essa unidade superior que concentra verdades isoladas, penetra as mais reconditas relações, e dá esperanças de um trabalho consciencioso" (TEIXEIRA DE FREITAS, Augusto. Consolidação das leis civis. $2^{2}$ ed. Rio de Janeiro, Typographia Universal de Laemmert, 1865. p. VII).

${ }^{6}$ Para tanto, basta lembrar a ponderação de Bobbio, segundo comenta o Prof. José Alcebíades de Oliveira Jr. (OLIVEIRA JR., José Alcebíades de. Bobbio, a ciência do Direito e a função social do jurista. Cadernos do Programa de Pós-Graduação em Direito - PPGDir-UFRGS, p. 39-52, mar. ${ }^{7}$, p. 40). 10 VIGO, Rodolfo. Interpretação jurídica: do modelo juspositivista-legalista do século XIX às novas perspectivas. Apresentação de Luiz Carlos de Azevedo. Tradução de S. Dalle Mura. Revisão e notas de Alfredo de J. Flores. São Paulo: RT, 2005. p. 36.

${ }^{8}$ Ver LOPES, José Reinaldo de Lima. Direito e transformação social. Belo Horizonte: Ed. Ciência Jurídica, 1997. p. 75.
} 
Quaestio Iuris

invenção contemporânea que resultasse do domínio de padrões de ciência que se pautam pelo empirismo. Na verdade, o que se nota desde a história do pensamento jurídico é que o debate sobre o papel do conhecimento particular do Direito nunca foi totalmente marginalizado, mesmo no período racionalista; ademais, o que a história acaba confirmando é a essência da metodologia jurídica tradicional, que, na ciência jurídica, sempre se busca a relação entre o particular e o universal.

O que se poderia afirmar, segundo já se comentou antes, é que o contexto atual, ávido de grandes mudanças, em que são demandadas respostas caso a caso, faz com que o estudo de caso se torne primordial, ainda mais nessa época de forte presença da experiência judicial. Mas é sempre preciso recordar que a metodologia contemporânea, que valoriza novamente a reflexão sobre os casos concretos, não é a única forma na história que conseguiu compreender o fenômeno jurídico - desde a Antigüidade Clássica, o Ocidente busca estabelecer esse equilíbrio entre a prática e a teoria, entre o particular e o universal, de onde o acerto do enfoque atual melhor se daria se buscasse aprender com os ensinamentos do passado.

\section{Referências}

DE LEIBNIZT, Godofredi Gvilielmi L. B. Nova methodvs discendæ docendæque Ivrisprvdentiæ, ex artis didacticæ principiis in parte generali præpræmissis, experientiæque luce. Lipsiæ et Halæ: Officina Krvgiana, MDCCXXXXVIII (Nachdr. Glashütten im Taunus: Detlev Auvermann KG, 1974).

FINNIS, John. Ley natural y derechos naturales. Tradução e estudo preliminar de Cristóbal Orrego. Buenos Aires: Abeledo-Perrot, 2000.

GENY, François. Science et technique en droit privé positif : nouvelle contribution à la critique de la méthode juridique. v. I. Paris : Recueil Sirey, 1913.

GÓMEZ ROBLEDO, Antonio. Ensayo sobre las virtudes intelectuales. México D.F.: Fondo de Cultura Económica, 1996.

LOPES, José Reinaldo de Lima. Direito e transformação social. Belo Horizonte: Ed. Ciência Jurídica, 1997.

MACHADO, Fábio. Do conhecimento jurídico, saber prático-prudencial. Direito \& Justiça. Porto Alegre: EDIPUCRS, v. 31, ano 27, p. 45-65, jul. 2005. 
Quaestio Iuris

OLIVEIRA JR., José Alcebíades de. Bobbio, a ciência do Direito e a função social do jurista. Cadernos do Programa de Pós-graduação em Direito - PPGDir-UFRGS, p. 39-52, mar. 2005.

RAMíREZ, Santiago. El concepto de filosofía. Tradução de J. García Lopez. Madrid: Ed. Leon, 1953.

SAVIGNY, Friedrich Carl von. Metodología jurídica. Tradução de J. J. Santa-Pinter. Buenos Aires: Depalma, 1994.

TEIXEIRA DE FREITAS, Augusto. Introdução. In: TEIXEIRA DE FREITAS, Augusto. Consolidação das leis civis. $2^{\mathrm{a}}$ ed. Rio de Janeiro, Typographia Universal de Laemmert, 1865.

VIGO, Rodolfo. Interpretação jurídica: do modelo juspositivista-legalista do século XIX às novas perspectivas. Apresentação de Luiz Carlos de Azevedo. Tradução de S. Dalle Mura. Revisão e notas de Alfredo de J. Flores. São Paulo: RT, 2005. 